\section{Journal of Biomedical and Pharmaceutical Research}

Available Online at www.jbpr.in

CODEN: - JBPRAU (Source: - American Chemical Society)

PubMed (National Library of Medicine): ID: (101671502)

Research Article

Volume 8, Issue 4: July-August: 2019, 56-61
ISSN (Online): 2279-0594

ISSN (Print): 2589-8752

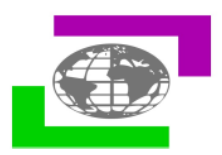

EFFECT OF PLANTAGO OVATA MUCILAGE USED AS NATURAL SUPERDISINTEGRANT ON RAPIMELTS TABLET OF METACLOPRAMIDE HCL

Abhinav Kumar Tripathi*, Dr. Hemendra Gautam

Shri Venkateshwara University, Gajraula (UP)

Article Info: Received 15 June 2019; Accepted 05 August. 2019

DOI: https://doi.org/10.32553/jbpr.v8i4.718

Address for Correspondence: Abhinav Kumar Tripathi, Research Scholer, Shri Venkateshwara University, Gajraula (UP)

Conflict of interest statement: No conflict of interest

\title{
ABSTRACT:
}

Formulation, development and optimization of rapimelts containing metoclopramide $\mathrm{HCl}$ using natural superdisintegrant to isolate mucilage from the plantago ovata husk powder by pregelatinization method. To prepare priliminary trial batches of repimelts using $\beta$ cyclodextrin with different ratio of drug and polymer. To evaluate the drug polymer complex and finally which polymer and ratio of drug and polymer is better to formulate final formulation. To achieve taste masking of drug. To prepare preliminary trial batches of rapimelts using plantago ovata mucilage as natural superdisintegrant and crosspovidone as synthetic superdisintegrant by direct compression method. To evaluate the prepared rapimelts for various properties like friability, hardness, wetting time, water absorption ratio, disintegration time, drug content, drug etc. Identifying the key variables and their levels for applying factorial design and to optimize one formulation. To evaluate the final batches and find out the optimized batch based on statistical optimization using experimental design. To compare the optimized formulation with marketed preparation. To carry out stability studies of optimized batch as per ICH guidelines. The aim of the present investigation was to Formulate, designed, and evaluates plant agoovata mucilage used as a natural superdisintegrant was to developed and optimized rapimelts containing Metoclopramide HCL.

Keywords: Rapimelt , Superdisintegrant, Rapimelt Super disintegrate, Metaclopramide hydrochloride

\section{INTRODUCTION}

Dosage forms are the means by which drug molecules are delivered to sites of action within the body ${ }^{1}$.

Tablets and capsules are the most popular and frequently dispensed medication dosage form because they are convenient for selfadministration and easily handled by the patient; however, there are many other different dosage forms available for patients.

Ever wonder why there are so many different dosage forms whenever you walk into a pharmacy to get a medication filled or to pick up an OTC item? Here are a couple of reasons: coated tablets protect the active ingredient/ drug substance from the destructive influences of oxygen and humidity; enteric-coated tablets protect the active ingredient from destruction from gastric acid in the stomach after oral administration; capsules, coated tablets, effervescent granules, flavored suspensions and solutions conceal bitter, salty, or bad tastes; lozenges, troches, gummy bears, ODT tablets, thin strips, lollipops, suspensions, and solutions provide formulations for patients, often children, who cannot swallow tablets or capsules; controlledrelease tablets, capsules, and suspensions provide rate-controlled medication release and action; ointments, creams, gels, patches, ear drops, eye drops, and nasal sprays provide optimal drug action from topical administration sites; ointments, creams, gels, suppositories, and enemas provide medication to patients who cannot take anything by mouth, either due to nausea/ vomiting or inability to swallow; and inhalers and nebulizers provide optimal drug therapy to the pulmonary system. 
Listed below are various dosage forms, including dosage forms to be taken by mouth, to be applied to the affected area (topical administration), to be inhaled, and to be inserted rectally. Each dosage form has unique physical characteristics and its own advantages and disadvantages. The availability of various dosage forms provides patients and providers with multiple ways to ensure the patient is able to take the prescribed medication. Regardless of dosage form, the medicinal agent must safe, stable, and efficacious ${ }^{2}$.

\section{Pharmaceutical Excipients}

The word excipientis derived from the Latin excipere, meaning 'to except', which is simply explained as 'other than'. Pharmaceutical excipients are basically everything other than the active pharmaceutical ingredient. Ideally, excipients should be inert, however, recent reports of adverse reactions have suggested otherwise.

What are excipients doing in medicines?

The best new therapeutic entity in the world is of little value without an appropriate delivery system ${ }^{3}$.Today, medicines are available in many dosage forms including tablets, capsules, oral liquids, topical creams and gels, transdermal patches, injectable products, implants, eye products, nasal products, inhalers and suppositories. Pharmaceutical excipients are substances that are included in a pharmaceutical dosage form not for their direct therapeutic action, but to aid the manufacturing process, to protect, support or enhance stability, or for bioavailability or patient acceptability. They may also assist in product identification and enhance the overall safety or function of the product during storage or use $\mathrm{e}^{4}$.

Thousands of different recipients are used in medicines and make up, on average, about $90 \%$ of each product. They represent a market value of $€ 3$ billion (almost $\$ 4$ billion) accounting for $0.5 \%$ of the total pharmaceutical market according to industry experts ${ }^{5}$.

\section{Common excipients used in tablets}

The list of purposes for which excipients are used, as defined in international pharmacopoeias, is extremely long. Many excipients have more than one use, which can be an advantage since it reduces the number of excipients needed and minimises the risk of interactions between them.
Tablets are the most widely used dosage form. Their manufacture can be a complex process and considerable ingenuity and formulation expertise are required to produce a product that will be stable during storage, transport and handling, yet will release its active pharmaceutical ingredient as required once ingested ${ }^{6}$.

\section{Adverse reactions to Excipients}

Ideally, an excipient is pharmacologically inactive, non-toxic, and does not interact with the active ingredients or other excipients. However, in practice few excipients meet these criteria. Toxicity may relate to compounds used as excipients in the final dosage form or to residues of compounds (such as solvents) used during the manufacturing process.

\section{Colouring agents}

Owing to their widespread and relatively large use in food, a number of colours in current use have been associated with adverse effects, although in a relatively small number of people ${ }^{7}$. The role of food additives in hyperactive behaviour has been debated for many years. In 2007 a study was published linking the use of six colours (tartrazine, quinoline yellow, sunset yellow, carmoisine, ponceau $4 R$ and allura red) with behavioural problems in children. However, after reviewing the results of the study, the European Food Standards Agency concluded that no change in legislation was needed ${ }^{7}$.

Identifying reactions to excipients in practice

When presented with a patient who has an adverse reaction, it is important to be aware that reactions may not always be due to the active ingredient. They are more likely to occur if the patient has an existing sensitivity to similar ingredients, or is on multiple medicines, or when the quantity of excipients may be high relative to body weight, for example in premature babies ${ }^{8}$. Excipients present in their current and past medication history should also be considered. This will help to rule out which ingredients may be causing the adverse effects ${ }^{8}$.

\section{Materials and Methods}

\section{Examination of drug by determining melting point:}

Melting point of Metoclopramide $\mathrm{HCl}$ was determined by Melting Point Apparatus. 
Metoclopramide $\mathrm{HCl}$ was filled in capillary tube and capillary tube as well as thermometer was kept in Melting Point Apparatus. The point at which Metoclopramide $\mathrm{HCl}$ melts is recorded from thermometer.

Examination of drug by UV spectrophotometer 38,39:

U.V. scan of Metoclopramide $\mathrm{HCl}$ in following media:

- In phosphate buffer pH 6.8

- In $0.1 \mathrm{~N} \mathrm{HCl}$ pH 1.2

-Resulting solutions of $20 \mu \mathrm{g} / \mathrm{ml}$ in $0.1 \mathrm{~N} \mathrm{HCl} \mathrm{pH} 1.2$ and $20 \mu \mathrm{g} / \mathrm{ml}$ prepared in

-Phosphate buffer $\mathrm{pH} 6.8$ were scanned between $200 \mathrm{~nm}$ to $400 \mathrm{~nm}$ using Double beam UV-visible spectrophotometer.

\section{Materials}

\section{ANALYTICAL METHOD DEVELOPMENT}

Standard calibration Plot of Metoclopramide $\mathrm{HCl}$ in phosphate buffer pH 6.8 and $0.1 \mathrm{~N} \mathrm{HCl} \mathrm{pH} 1.2$

\section{- Standard (Stock) solutions:}

An accurately weighed $10 \mathrm{mg}$ of Metoclopramide $\mathrm{HCl}$ was dissolved and diluted to $100 \mathrm{ml}$ with phosphate buffer $\mathrm{pH} 6.8$ and $0.1 \mathrm{~N} \mathrm{HCl}$ to produce $100 \mu \mathrm{g} / \mathrm{ml}$ stock solutions.

\section{- Preparation of Sample solutions:}

Different dilution of stock solution were prepared using Phosphate buffer $\mathrm{pH} 6.8$ and $0.1 \mathrm{~N} \mathrm{HCl}$ to obtain solution having concentration $4,8,12,16$, $20 \mu \mathrm{g} / \mathrm{ml}$ in both the media and absorbances were measured at obtained $\lambda$ max of $273 \mathrm{~nm}$.

\section{Isolation of Plantago ovata mucilage}

The husk of Plantago ovata was powdered and passed through a no. 80 screen. The powder was soaked in distilled water for $24 \mathrm{~h}$ and boiled for a few minutes, so that complete gelatinization takes place and dried in an oven at a temperature less than $60^{\circ} \mathrm{C}$. After drying gelatinized material was collected, and size reduced.

\section{FORMULATION AND DEVLOPMENT}

Preparation of Rapimelts by Direct Compression Technique

Rapimelts of Metoclopramide $\mathrm{HCl}$ were prepared by direct compression method according to the formula given in table. All the ingredients were passed through 60 mesh sieve separately. The drug and mannitol were mixed by small portion of both and blended to get a uniform mixture. Rest of the ingredients were weighed and mixed in geometrical proportion with MetoclopramideMannitol mixture and tablets were directly compressed using $9 \mathrm{~mm}$ sizes flat round punch on 10 stations, B tooling Rotary Tablet Compression Machine.

Preliminary study

- Taste masking of Metoclopramide $\mathrm{HCl}$ by complexing with $\beta$ -

cyclodextrin14 Preparation :

Solid complexes of Metoclopramide $\mathrm{HCl}-\beta-\mathrm{CD}$ were prepared in 1:1, 1:2 and

1:3 molar ratios by kneading methods.

Evaluation of Drug-Polymer Complex

- \% Yield: It is calculated using following formula

Percentage yield $=[\mathrm{Wp} / \mathrm{Wt}] \times 100$

Where, $W p=$ actual weight of taste masked particles obtained and

$\mathrm{Wt}=$ total weight of drug + polymer

(metoclopramide $\mathrm{HCl}$ and $\beta$-cyclodextrin).

\section{B. Evaluation Tests for Rapimelts}

\section{- $\quad$ Pre Compression Evaluation}

Pre compression evaluation studies were carried out for following parameter

i.e. Bulk density, Tapped density, Hausner's ratio, Carr's index, Compressibility index. These parameters were evaluated on a laboratory scale for preparation of tablets with good flow properties of powder material.

- $\quad$ Bulk density (Do)

It is the ratio of bulk volume to the total mass of the powder taken. It was measured by pouring the weighed powder into a $25 \mathrm{ml}$ graduated cylinder and the volume was noted. It is given by:

- $\quad D o=M /$ Vo

Where, ' $M$ ' is the mass of powder,

' $V o$ ' is the Bulk Volume of powder; it is expressed in $\mathrm{g} / \mathrm{ml}$. 


\section{- $\quad$ Tapped density (Dt)}

It is the ratio of mass of the powder to the tapped volume of the powder. The tapped volume was measured by bulk density apparatus in which the powders were tapped for predetermined number of taps until the volume became constant.

It is given by formula:

- $\quad D t=M / V t$

Where, ' $M$ ' is the mass of powders

' $\mathrm{Vt}$ ' is the tapped volume of powders; it is expressed in $\mathrm{g} / \mathrm{ml}$.

\section{- Carr's index}

It is the \%compressibility index. It is given by

$\mathrm{I}=(\mathrm{Dt}-\mathrm{Do} / \mathrm{Do}) \times 100$

Where, ' $\mathrm{Dt}$ ' is tapped density

'Do' is bulk density; it is expressed in terms of percentage.

Limit: <16- Excellent flow,

16-20-Good flow,

$>20$-poor flow.

- Hausner's ratio

It is the ratio of tapped density to untapped density. It is given by

$H=D t / D o$

Where, ' $D t$ ' is the tapped density of powders

'Do' is the untapped density of powders.

Limit: $<1.25-$ Good flow

1.25-1.5- Fair to Passable

$>1.5$ - Poor flow

\section{Angle of Repose}

The angle of internal friction is a measure of internal stress distribution and is the angle at which an applied stress diverges as it passes through the bed. It is the least slope at which a powder will slide down an inclined plane surface. It is denoted by $\boldsymbol{\theta}$. Angle of repose was determined using fixed funnel method.

The blend was poured through funnel fixed at a height of $2 \mathrm{~cm}$, until a maximum cone height (h) was obtained. Radius of the heap ( $r$ ) was measured and angle of repose was calculated using the formula

$\tan -1 \theta=h / r$

The values of angle of repose obtained can be interpreted as follows:

\section{Post Compression Evaluation}

\section{- Weight variation}

As per U.S.P. procedure, 20 tablets were selected randomly from the lot and weighed individually on digital weighing balance to check for weight variation. Weight variation specification as per U.S.P is shown ahead.

\section{- Tablet Thickness}

Micrometer was used for the measurement of thickness of tablet. Ten tablets were taken and their thickness recorded. The mean value was calculated and standard deviation was determined.

\section{- Hardness}

Hardness or tablet crushing strength $(\mathrm{fc})$ means the force required to break a tablet in a diametric compression was determined using Pfizer/Monsanto tablet hardness tester. It is expressed in $\mathrm{kg} / \mathrm{cm} 2$. The hardness of Rapimelts is kept lower than conventional tablet because increase in hardness delays the disintegration of tablet. Five tablets from each batch were randomly selected and average hardness was calculated and standard deviation was determined.

\section{- $\quad$ Friability}

Friability of the tablet was determined using Roche friabilator. This device subjects the tablet to the combined effect of abrasion and shock in a plastic chamber revolving at $25 \mathrm{rpm}$ and dropping a tablet at height of 6 inches in each revolution. Tablets, 10 were preweighed and placed in the friabilator and the equipment was rotated at $25 \mathrm{rpm}$ for $4 \mathrm{~min}$. Tablets were dusted and weighed again. \% Friability should be less than $1 \%$ The friability (F) is given by the formula.

\section{$\% \mathrm{~F}=$ (loss in weight/Initial weight $) \times 100$}

\section{- Wetting Time}

A piece of tissue paper $(12 \mathrm{~cm} \mathrm{X} 10.75 \mathrm{~cm})$ folded twice was placed in a small petridish $(I D=10 \mathrm{~cm})$ containing $6 \mathrm{ml}$ of Phosphate Buffer $\mathrm{pH}$ 6.8. A 
tablet was placed on the paper, and the time for complete wetting was measured. Five tablets from each batch were analyzed. The mean value was calculated and standard deviation was determined.

\section{- Content Uniformity}

Content uniformity was determined as per USP specifications for 10 tablets from each batch. Tablet was dispersed in $50 \mathrm{ml}$ of phosphate buffer $\mathrm{pH} 6.8$ and sonicated for $30 \mathrm{~min}$. Volume was made up to $100 \mathrm{ml}$ with phosphate buffer $\mathrm{pH} 6.8$ and filtered using Whatman filter paper. Filtrate was analyzed for Metoclopramide $\mathrm{HCl}$ content by measuring UV absorbance at $273 \mathrm{~nm}$. To pass the test, all the 10 tablets must show drug content in the range of $85-115 \%$. Not more than 1 tablet sholud show the drug content in the range of 75 $125 \%$.

\section{- In-Vitro Dispersion Time}

In vitro dispersion time was measured by dropping a tablet in a $10 \mathrm{ml}$ measuring cylinder containing 6 $\mathrm{ml}$ of buffer solution simulating saliva fluid ( $\mathrm{pH}$ 6.8) at $37+0.5 \circ \mathrm{C}, 5$ tablets were randomly selected and time required for complete dispersion of a tablet was measured. Average dispersion time and standard deviation was determined.

\section{- In-Vitro Disintegration Time}

Disintegration time for Rapimelts was determined using USP disintegration apparatus in Phosphate buffer $\mathrm{pH} 6.8$, volume $900 \mathrm{ml}$ at $37^{\circ} \mathrm{C}$ temperature.
To comply the test all tablets should disintegrate within 3 minutes.

\section{- In-Vitro Dissolution test for drug release}

In vitro dissolution test of Metoclopramide $\mathrm{HCl}$ Tablet was done by following two methods:

- $\quad$ In 0.1N HCl: Dissolution was carried out using USP dissolution test apparatus type 2 (paddle) at $50 \mathrm{rpm}$ in $300 \mathrm{ml}$ of $0.1 \mathrm{~N} \mathrm{HCl}(\mathrm{pH} \mathrm{1.2)}$ as dissolution media, maintained at $37+0.5$ ㅇ․ $3 \mathrm{ml}$ of sample was withdrawn from the dissolution medium at the specified regular intervals, filtered through Whatmann filter paper and assayed spectrophotometrically at $\lambda \max 273 \mathrm{~nm}$.

In phosphate buffer pH 6.8: Dissolution placed on magnetic stirrer, maintained at 50rpm and $37+0.5$ ㅇ. $3 \mathrm{ml}$ of sample was withdrawn from it at the specified regular intervals, filtered through Whatmann filter paper and assayed spectrophotometrically. An equal volume of pre warmed ( $37 \stackrel{\circ}{ } \mathrm{C}$ ) fresh mediun is replaced into the dissolution medium after each sampling to maintain the constant volume throughout the test.

\section{Results}

Metoclopramide $\mathrm{HCl}$ was found to be $183^{\circ} \mathrm{C}$ which was similar to that of standard values thus indicating the purity of the drug and all other laboratory observations were almost similar to the reported values.

Table 1:

\begin{tabular}{|c|c|c|}
\hline Sr. No & Evaluation Parameter & Results \\
\hline 1. & Organoleptic properties;state. Color, odour, Taste, Fracture & Solid, Off White-Lightish Brown, Characteristic, Bland, Smooth. \\
\hline 2. & $\mathrm{pH}$ & 7.4 \\
\hline 3. & Solubility & Soluble in hot water forming colloidal solution insoluble in organic solvent \\
\hline 4. & Swelling index & $25.7 \mathrm{ml}$ \\
\hline 5. & Total ash & $1.68 \%$ \\
\hline 6. & Moisture content & $1.7 \%$ \\
\hline 7. & Bulk density and tapped density & 0.62 to 0.74 \\
\hline 8. & Angle of repose & 32.70 \\
\hline 9. & Carr's index & 198.3 \\
\hline 10. & Hausner's ratio & 1.19 \\
\hline 11. & \%yield & $95 \%$ \\
\hline 12. & Particle size analysis & $15-65 \mu \mathrm{m}$ \\
\hline 13. & Estimation of total mucilage content & $77.57 \%$ \\
\hline 14. & Total microbial count & $<100$ cfu/g \\
\hline
\end{tabular}




\section{Discussion}

The aim of the present investigation was to Formulate, designed, and evaluates plant agoovata mucilage used as a natural superdisintegrant was to developed and optimized rapimelts containing Metoclopramide HCL. To purpose of the study isolate mucilage from the plantago ovata husk powder by pregelatinization method and prepared priliminary trial batches of repimelts using $\beta$ cyclodextrin with different ratio of drug and polymer. Evaluate the drug polymer complex and finally which polymer and ratio of drug and polymer is better to formulate final formulation. To achieve taste masking of drug. prepare preliminary trial batches of rapimelts using plantago ovata mucilage as natural superdisintegrant and crosspovidone as synthetic superdisintegrant by direct compression method. Rapimelts tablet of metoclopramide $\mathrm{Hcl}$ tablets by determination of range of technological parameters. Dissolution profile suggested that tablet prepared with Plantago ovate mucilage were capable of releasing up to $90 \%$ drug within 15 minutes in phosphate buffer $6.8 \mathrm{pH}$, by an appropriate combination of excipients it is thus possible to obtain Rapimelts tablet of metoclopramide $\mathrm{Hcl}$ tablets using simple and conventional technique.

\section{Conclusion}

To purpose of the study isolate mucilage from the plantago ovata husk powder by pregelatinization method and prepared priliminary trial batches of repimelts using $\beta$ cyclodextrin with different ratio of drug and polymer. Evaluate the drug polymer complex and finally which polymer and ratio of drug and polymer is better to formulate final formulation. To achieve taste masking of drug. prepare preliminary trial batches of rapimelts using plantago ovata mucilage as natural Superdisintegrant and crosspovidone as synthetic superdisintegrant by direct compression method.
Rapimelts tablet of metoclopramide $\mathrm{Hcl}$ tablets by determination of range of technological parameters. Dissolution profile suggested that tablet prepared with Plantago ovate mucilage were capable of releasing up to $90 \%$ drug within 15 minutes in phosphate buffer $6.8 \mathrm{pH}$, by an appropriate combination of excipients it is thus possible to obtain Rapimelts tablet of metoclopramide $\mathrm{Hcl}$ tablets using simple and conventional technique.

\section{References}

1. Augsburger LL, Zellhofer MJ. Tablet formulation. In: Swarbrick J, Boylan JC, editors. Encyclopedia of pharmaceutical technology. 3rd ed. New York: Marcel Dekker; 2006.

2. Martindale: The complete drug reference. 37th ed. London: Pharmaceutical Press; 2011. (electronic and hard copy available)

3. International Excipients Certification Project: minimize risks - maximize benefits. London: Pharmaceutical Quality Group; 2009.

4. Armstrong NA. Tablet manufacture. In: Swarbrick J, Boylan JC, editors. Encyclopedia of pharmaceutical technology. 3rd ed. New York: Marcel Dekker; 2006.

5. Rowe RC, Sheskey PJ, Quinn ME, editors. Handbook of pharmaceutical excipients. 6th ed. London: Pharmaceutical Press; 2009.

6. What are excipients doing in medicinal products? Drug Ther Bull 2009;47:81-4

7. Pandey Shivanand, Viral Devmurari, Manish Goyani, "Formulation and Evaluation of Taste Masked Fast Disintegrating Tablets of Lisinopril", International Journal of PharmTech Research, 2010, 2, 1639-1643.

8. S. K. Sheth, "Formulation and evaluation of taste masked oral disintegrating tablet of lornoxicam", International journal of pharma and biosciences, 2010,1, 1-9. 